\title{
Desenvolvimento de agregados leves a partir de resíduo de corte de pedras ornamentais (granitos e mármores) e argila
}

\section{Development of lightweight aggregates from crushing of ornamental stones (granites and marbles) and clay}

\author{
Nathaly Santana Leal de Souza ${ }^{1}$, Marcos Alyssandro Soares dos Anjos ${ }^{2}$, \\ Maria das Vitórias Vieira Almeida de Sá ${ }^{3}$, Evilane Cássia de Farias ${ }^{3}$, \\ Larissa Cavalcante de Araújo Mello ${ }^{3}$
}

\footnotetext{
${ }^{1}$ Programa de Pós-graduação em Engenharia Civil (PEC), Departamento de Engenharia Civil, Universidade Federal do Rio Grande do Norte (UFRN), R. das Engenharias, S/N, Lagoa Nova, CEP 59078-900, Natal, RN, Brasil.

${ }^{2}$ Instituto Federal de Educação, Ciência e Tecnologia da Paraíba (IFPB) e PEC/UFRN - Av. Treze de Maio, 720, Jaguaribe, CEP 58015-43, João Pessoa, PB, Brasil.

${ }^{3}$ Programa de Pós-graduação em Engenharia Civil (PEC), Departamento de Engenharia Civil, Universidade Federal do Rio Grande do Norte (UFRN), R. das Engenharias, S/N, Lagoa Nova, CEP 59078-900, Natal, RN, Brasil. e-mail: nathalysleal@gmail.com,marcos.anjos@ifpb.edu.br, vitoria@ct.ufrn.br, evilane.farias@ifrn.edu.br, larissa.engciv@yahoo.com.br
}

\begin{abstract}
RESUMO
Agregados leves são materiais granulares com estrutura porosa utilizados como isolantes térmico e acústico, decoração em paisagismos, na produção de enchimentos leves, em obras de drenagem, de aterros leves e de infraestrutura, além do uso para cultura hidropônica. Fabricados a partir de precursores argilosos, sinterizados a altas temperaturas, que se expandem devido a uma fase vítrea capturar os gases gerados, sendo os teores de fundentes e substâncias formadoras de gases, fatores intervenientes do processo. Nesse contexto verificou-se a possibilidade de utilização de resíduo de corte de granitos e mármores (RGM) e argila com objetivo de desenvolver agregados leves. Os precursores foram caracterizados quanto a área superficial (BET), granulometria a laser, finura, massas específica e unitária além das análises térmica (DTA/TG), química (FRX) e mineralógica (DRX). Foram produzidos agregados com teores de 0, 50, 60, 70, 80, 90 e 100\% de RGM, submetendo-os à sinterização em temperaturas de $1000^{\circ} \mathrm{C}$ a $1263^{\circ} \mathrm{C}$ em forno mufla. As misturas sinterizadas foram analisadas por sua massa específica aparente, absorção de água, massa unitária, módulo de deformação dos agregados leves, índice de inchaço, perda de massa, índice de encolhimento na secagem, análise visual, resistência à tração e morfologia por microscopia eletrônica de varredura (MEV). Após sinterização obteve-se agregados com massa específica aparente inferiores a $2,00 \mathrm{~g} / \mathrm{cm}^{3}$, absorção de água inferior a $20 \%$ e massa unitária inferior a $0,88 \mathrm{~g} / \mathrm{cm}^{3}$, valores estes definidos como requisitos para classificar um agregado como leve e de qualidade para utilização em concretos estruturais. Quanto as propriedades destacadas, foi possível desenvolver agregados leves com alto teor de resíduo que atendem aos requisitos normativos, respectivamente com valores de $1,56 \mathrm{~g} / \mathrm{cm}^{3}, 8 \%$ e $0,85 \mathrm{~g} / \mathrm{cm}^{3}$, além de agregados leves apresentando resistência à tração 4 vezes superior em relação ao agregado leve comercial.
\end{abstract}

Palavras-chave: agregado leve artificial, resíduo de corte de granitos e mármores, sinterização, argila expandida.

\section{ABSTRACT}

Lightweight aggregates are granular materials with porous structure used as thermal and acoustic insulation, decoration in landscaping, the production of light fillings, drainage works, light landfills and infrastructure, as well as hydroponics. Manufactured from clayey precursors, sintered at high temperatures, which expand due to a glassy phase to capture the gases generated, being the flux content and substances that form gases, intervening factors of the process. In this context, it was verified the possibility of using granite and marble 
cutting waste $(\mathrm{GMCW})$ and clay with the objective of developing lightweight aggregates. The precursors were characterized as surface area (BET), laser granulometry, fineness, specific gravity and bulk density in addition to thermal (ADT/TG), chemical (XRF) and mineralogical (XRD) analyzes. Aggregates with 0, 50, $60,70,80,90$, and $100 \%$ GMCW contents were produced by sintering at temperatures of $1000^{\circ} \mathrm{C}$ to $1263^{\circ} \mathrm{C}$ in a muffle furnace. The sintered mixtures were analyzed for their particle density, water absorption, bulk density, modulus of deformation of the lightweight aggregates, swelling index, mass loss, dry shrink index, visual analysis, tensile strength and morphology by scanning electron microscopy (SEM). After sintering, aggregates with particle density less than $2,00 \mathrm{~g} / \mathrm{cm}^{3}$, water absorption less than $20 \%$ and bulk density less than $0,88 \mathrm{~g} / \mathrm{cm}^{3}$ were obtained, these values being defined as requirements for classifying an aggregate as light and qualified for use in structural concrete. As for the highlighted properties, it was possible to develop lightweight aggregates with high waste content that meet the normative requirements, respectively, with values of $1,56 \mathrm{~g} / \mathrm{cm}^{3}, 8 \%$ and $0,85 \mathrm{~g} / \mathrm{cm}^{3}$, in addition to lightweight aggregates presenting tensile strength fourfold higher than the commercial lightweight aggregate.

Keywords: Artificial lightweight aggregate, granite and marble cutting waste, sintering, expanded clay.

\section{INTRODUÇÃO}

Agregados leves são materiais granulares e de estrutura porosa que são produzidos e comercializados por diversas empresas ao redor do mundo, oferecendo soluções diversas com o uso desses. Alguns exemplos de fabricantes são: CINEXPAN® (Brasil), Leca ${ }^{\circledR}$ (Portugal), Lytag $®$ (Reino Unido) e Liapor $®$ (Alemanha e Áustria). Entre as aplicações sugeridas pelos fabricantes estão os usos como isolante térmico e acústico, decoração em paisagismos, na produção de enchimentos leves, em obras de drenagem, de aterros leves e de infraestrutura, além do uso para cultura hidropônica.

De acordo com a ASTM C 331 [1], é necessário que os agregados leves miúdos e graúdos não excedam $1120 \mathrm{~kg} / \mathrm{m}^{3}$ e $880 \mathrm{~kg} / \mathrm{m}^{3}$, respectivamente, de massa unitária. Já a norma EN 13055 [2] define o agregado leve como um material granular de origem mineral com massa específica aparente inferior a $2000 \mathrm{~kg} / \mathrm{m}^{3}$ ou massa unitária solta inferior a $1200 \mathrm{~kg} / \mathrm{m}^{3}$.

Os agregados leves artificiais são formados pelo rápido aquecimento de materiais que têm a capacidade de se expandir a temperaturas muito altas, e, produzi-los a partir de resíduos é considerado uma alternativa ambiental muito satisfatória, uma vez que produtos anteriormente sem valor tornam-se matérias-primas com aplicações importantes [3].

Diferentes resíduos podem ser utilizados para a produção de agregados leves através de sinterização, estes materiais devem ser capazes de produzir um núcleo poroso e de baixa densidade, uma camada superficial com baixa absorção de água e uma forma quase esférica para melhorar as propriedades do concreto no estado fresco [4]. Para isto se utiliza matéria-prima com características argilosas com teores adequados de fundentes e substâncias formadoras de gases, que, queimadas a altas temperaturas, proporcionam a formação de uma fase vítrea que retém os gases gerados na queima, provocando a expansão [5].

A produção de agregados leves envolve diversos parâmetros como composição química das matériasprimas, moldagem dos grãos, perfil de queima, no que se refere às taxas de aquecimento, temperaturas de sinterização, realização ou não de pré-aquecimento, tipo de forno utilizado e resfriamento, além do controle tecnológico através de ensaios básicos que iram caracterizar o agregado produzido e classifica-lo ou não como agregado leve.

O resíduo de corte de granitos e mármores (RGM) é normalmente armazenado em forma de lama nas indústrias de rochas ornamentais. Durante o processo de corte e polimento das rochas utiliza-se água para o arrefecimento dos discos e diminuição do pó em suspensão, e, essa mistura de água, pó e resíduos formam a lama de RGM. Calhas e dutos direcionam a lama até o local (tanque) de armazenamento na fábrica para posterior destinação do resíduo.

Agregados leves com composições de RGM e argila provenientes da cidade de Cairo/Egito foram produzidos [6], com teores de RGM variando de $50 \%$ a $100 \%$, e, as temperaturas de sinterização variaram de $1000^{\circ} \mathrm{C}$ a $1200^{\circ} \mathrm{C}$, com tempo de exposição de $15 \mathrm{~min}$, e, rampa de aquecimento de $10^{\circ} \mathrm{C} / \mathrm{min}$. A massa unitária dos agregados produzidos pelos autores diminuiu com o aumento da temperatura máxima de queima, e, os agregados leves, de massa unitária inferior ou igual a $1,2 \mathrm{~g} / \mathrm{cm}^{3}$, somente foram alcançados após a queima das misturas contendo pelo menos $20 \%$ em peso de argila à $1200^{\circ} \mathrm{C}$, sendo os menores valores registrados para essa propriedade de $0,65 \mathrm{~g} / \mathrm{cm}^{3}$.

O uso de RGM em conjunto com argila e adição de resíduos de fibras de carbono ou com rejeitos plásticos também foi estudado [7,8], e, após avaliação do tempo e temperatura nos fornos para produção de agregados leves verificou-se a necessidade de inclusão de aditivos das fibras de carbono ou rejeitos plásticos 
para a produção de agregados leves com características adequadas, pois, agregados produzidos com apenas a base mineral (RGM + argila) diminuíram de volume com o aumento da temperatura e o tempo de exposição, produzindo agregados de densidade pesada.

Nesse contexto, objetiva-se neste trabalho determinar as misturas ideais entre RGM e argila regional e avaliar as temperaturas para sinterização que proporcionem as propriedades adequadas para uso como agregado leve. Pretende-se ainda, fomentar a pesquisa de agregados leves na região Nordeste brasileira utilizando as matérias primas locais, com o intuito de desenvolver agregados leves inovadores como opção ao agregado leve graúdo atualmente comercializado no Brasil.

\section{MATERIAIS E MÉTODOS}

\subsection{Precursores}

A argila branca regional (ARG-B) utilizada é proveniente do município de Equador/RN/Nordeste/Brasil, já beneficiada, sendo passada na peneira de 325 mesh (abertura de $0,044 \mathrm{~mm}$ ), gentilmente cedida por uma indústria fabricante de peças cerâmicas em especial porcelanatos.

O resíduo de corte de granitos e mármores (RGM) utilizado nesta pesquisa é proveniente de uma marmoraria localizada no município de Parnamirim/RN/Nordeste/Brasil, que gentilmente forneceu o resíduo em forma de lama. A lama foi beneficiada no Laboratório de Durabilidade e Química dos Materiais IFRN/Campus Natal-Central, onde passou por homogeneização, decantação e eliminação do excesso de água, secagem ao ar livre e em estufa à $110 \pm 5^{\circ} \mathrm{C}$ até constância de massa. Por fim realizou-se o peneiramento do material seco resultando em um pó fino passado na peneira de abertura $0,15 \mathrm{~mm}$ (100 mesh).

\subsection{Caracterização dos precursores}

A caracterização das matérias primas ARG-B e RGM foi realizada a partir de ensaios de caracterização física, análises químicas, térmicas e mineralógicas descritas a seguir.

A granulometria à laser foi realizada no Laboratório de Materiais Metálicos da UFPB-Campus João Pessoa, em equipamento de modelo CILAS 1090, por via seca, na faixa de 0,10 a $500 \mu \mathrm{m}$, com 100 classes.

A área superficial - BET foi obtida a partir de equipamento Modelo BEL-SORP II-MINI, que opera através de adsorção/dessorção de nitrogênio a 77K. As amostras passaram inicialmente por tratamento térmico a $200^{\circ} \mathrm{C}$ por $2 \mathrm{~h}$, em fluxo de nitrogênio, e, todo o procedimento foi realizado Laboratório de Caracterização e Desenvolvimento de Nanomateriais do IFPB-Campus João Pessoa.

A análise química por foi realizada por fluorescência de raios-X (FRX) em equipamento modelo EDX-720, no Laboratório de Caracterização Estrutural dos Materiais/DEMAT/CT/UFRN. No mesmo laboratório, foi realizada a análise da composição mineralógica por difratometria de Raios-X (DRX), utilizando voltagem de $40 \mathrm{kV}$, corrente de $30 \mathrm{~mA}$, velocidade de $1 \% \mathrm{~min}$, passo de amostragem de $0,02^{\circ}$ com varredura contínua na faixa de 5 a $70^{\circ}$.

A análise térmica foi realizada por termogravimetria (TG) e por análise térmica diferencial (DTA), em equipamento modelo DTG-60H em atmosfera de nitrogênio com vazão de $100 \mathrm{ml} / \mathrm{min}$ e taxa de aquecimento de $10^{\circ} \mathrm{C} / \mathrm{min}$, com intervalo de temperatura entre $10^{\circ} \mathrm{C}$ e $1000^{\circ} \mathrm{C}$, utilizando célula de alumina e massas de amostras na ordem de $12 \mathrm{mg}$. As análises foram realizadas no LabTer - Laboratório de Análises Térmicas da UFCG, na Unidade Acadêmica de Engenharia de Materiais (UAE-Ma-CCT).

No Laboratório de Durabilidade e Química dos Materiais - IFRN/Campus Natal-Central, foram realizados os ensaios de finura, massa unitária e massa específica. As finuras dos materiais foram realizadas com base na NBR 11579 [9]. A massa unitária foi determinada com equipamento modelo 1.103.900, composto por funil padrão com registro de descarga e copo com volume de um litro que possibilita a determinação da densidade aparente de materiais finos. Já a massa específica foi determinada a partir do frasco volumétrico de Le Chatelier, com base na norma NBR 16605 [10].

\subsection{Misturas, moldagem e parâmetros de queima}

Foram produzidas misturas com 100\% de ARG-B e 100\% de RGM e composições binárias de ARG-B e RGM com teores de RGM variando de $50 \%$ a $90 \%$, em massa. Os teores de umidade foram estimados a partir dos ensaios de Limite de Liquidez - LL [11] e Limite de Plasticidade-LP [12]. Onde, partiu-se do intervalo de umidade dada pelo LL e LP, selecionando um valor comum a todas as composições, com o objetivo de manter os valores de umidade das misturas o mais próximo possível.

A mistura, homogeneização e pelotização dos agregados foi realizada manualmente, e visando manter 
homogeneidade de tamanho dos mesmos, a fim de diminuir a variável granulométrica, as massas úmidas foram pesadas em balança com precisão de $0,01 \mathrm{~g}$ até a massa de $1 \mathrm{~g} \pm 0,1 \mathrm{~g}$ e posteriormente moldadas. E, devido ao procedimento ser realizado manualmente a umidade prevista podia ser ajustada durante o processo. Na Tabela 1 são apresentadas as composições, os teores de matérias-primas, Limites de Atterberg, as umidades de moldagem (UM), além do teor de $\mathrm{SiO}_{2}, \mathrm{Al}_{2} \mathrm{O}_{3}$ e somatório de óxidos fundentes ( $\mathrm{OF}$ ) das misturas.

Tabela 1: Composições e seus respectivos valores de LL, LP, índice de plasticidade (IP) e umidade de moldagem (UM), além dos teores de $\mathrm{SiO}_{2}, \mathrm{Al}_{2} \mathrm{O}_{3}$ e $\Sigma \mathrm{OF}$ das misturas.

\begin{tabular}{|c|c|c|c|c|c|c|c|c|c|}
\hline \multirow{2}{*}{ COMPOSIÇÃO } & \multicolumn{2}{|c|}{ (\%) PRECURSOR } & \multirow{2}{*}{ LL } & \multirow{2}{*}{ LP } & \multirow{2}{*}{$\begin{array}{c}\text { IP } \\
(\mathrm{IP}=\mathrm{LL}-\mathrm{LP}) \\
\end{array}$} & \multirow{2}{*}{ UM } & \multicolumn{3}{|c|}{ (\%) COMPOSIÇÃO QUÍMICA } \\
\hline & ARG-B & RGM & & & & & $\mathrm{SIO}_{2}$ & $\mathrm{AL}_{2} \mathrm{O}_{3}$ & $\Sigma O F$ \\
\hline ARG-B & 100 & 0 & 44 & 31 & 13 & 40 & 55,94 & 42,05 & 2,00 \\
\hline RGM- $50 \%$ & 50 & 50 & 31 & 20 & 11 & 29 & 47,99 & 24,62 & 27,39 \\
\hline RGM-60\% & 40 & 60 & 29 & 18 & 11 & 28 & 46,40 & 21,13 & 32,47 \\
\hline RGM-70\% & 30 & 70 & 26 & 18 & 8 & 28 & 44,81 & 17,64 & 37,55 \\
\hline RGM- $80 \%$ & 20 & 80 & 25 & 20 & 5 & 27 & 43,22 & 14,16 & 42,63 \\
\hline RGM-90\% & 10 & 90 & 25 & 19 & 6 & 27 & 41,63 & 10,67 & 47,70 \\
\hline RGM- $100 \%$ & 0 & 100 & 23 & 18 & 5 & 28 & 40,03 & 7,18 & 52,78 \\
\hline
\end{tabular}

As sinterizações foram realizadas no Laboratório de Nutrição Animal da Escola Agrícola de JundiaíEAJ/UFRN, no distrito de Jundiaí - Macaíba/RN, em forno mufla com capacidade de 701, dimensões úteis de $40 \mathrm{~cm} \times 40 \mathrm{~cm} \times 45 \mathrm{~cm}$, modelo JC7013, que atinge temperaturas de até $1300^{\circ} \mathrm{C}$, e, com controlador de tempo e temperatura do modelo J300. Para a proteção do forno mufla, foram utilizadas plaquetas refratárias para forrar o equipamento e dispor sobre essas os agregados para sinterização. A identificação dos agregados foi realizada pela localização dos mesmos sobre as plaquetas refratárias.

A rampa de aquecimento, o patamar de exposição e as temperaturas máximas adotadas foram escolhidas com base em trabalhos anteriores. Assim como SOLTAN et al. [6], utilizou-se neste estudo a taxa de aquecimento de $10^{\circ} \mathrm{C} / \mathrm{min}$, patamar de $15 \mathrm{~min}$ e temperaturas máximas de $1000^{\circ} \mathrm{C}, 1050^{\circ} \mathrm{C}, 1100^{\circ} \mathrm{C}, 1150^{\circ} \mathrm{C} \mathrm{e}$ $1200^{\circ} \mathrm{C}$. Após ensaios realizados, verificou-se que as misturas não sofreram grandes alterações até a temperatura de $1200^{\circ} \mathrm{C}$, então realizou-se queimas em temperaturas mais altas até que fosse possível identificar a variação física dos agregados em função da temperatura. Dessa forma foram então acrescentadas as temperaturas de $1213^{\circ} \mathrm{C}, 1225^{\circ} \mathrm{C}, 1238^{\circ} \mathrm{C}, 1250^{\circ} \mathrm{C}$ e $1263^{\circ} \mathrm{C}$, isto demonstra a importância em se avaliar as matériasprimas locais e temperaturas para obtenção de agregados leves.

\subsection{Estudo dos agregados produzidos}

O estudo dos agregados envolveu os ensaios de índice de encolhimento, índice de inchaço, perda de massa, massa específica aparente, absorção de água, módulo de deformação dos agregados leves, massa unitária e análise visual, realizados no Laboratório de Durabilidade e Química dos Materiais/DIACON/IFRN-Campus Natal-Central, resistência ao esmagamento, realizado no Laboratório de Propriedades Físicas dos Materiais Cerâmicos-LaPFiMC/UFRN e análise de microscopia de varredura eletrônica (MEV), realizada no Laboratório de Caracterização de Minerais/Materiais-LACAMM/DIAREN/IFRN-Campus Natal-Central.

O índice de encolhimento foi calculado com base na média de diâmetros medidos, com paquímetro digital de precisão de $0,01 \mathrm{~mm}$, em 4 direções distintas em cada agregado, logo após moldagem (condição úmida) e após secagem em estufa a $100^{\circ} \mathrm{C}$ (condição seca), conforme Equação (1). O resultado do ensaio para cada mistura representa a média de determinações realizadas em 30 agregados.

$$
I E=\frac{D_{m u}-D_{m d}}{D_{m u}} \times 100
$$

onde,

IE é o Índice de encolhimento do agregado (\%);

$D_{m d}$ é a média aritmética dos diâmetros na condição seca (mm); e,

$D_{m u}$ é a média aritmética dos diâmetros na condição úmida $(\mathrm{mm})$.

$\mathrm{O}$ índice de inchaço foi calculado com base na média de diâmetros medidos, com paquímetro digital 
de precisão de $0,01 \mathrm{~mm}$, em 4 direções distintas do agregado, na condição seca em estufa a $100^{\circ} \mathrm{C}$ e após sinterização, conforme Equação (2). O resultado do ensaio representa a média de 10 determinações (agregados).

$$
I I=\frac{D_{m s}-D_{m d}}{D_{m d}} \times 100
$$

onde,

II é o Índice de inchaço do agregado (\%);

$D_{m s}$ é a média aritmética dos diâmetros na condição sinterizada (mm); e,

$D_{m d}$ é a média aritmética dos diâmetros na condição seca $(\mathrm{mm})$.

A perda de massa foi calculada com base na medida de massa de cada agregado, na condição seca e após sinterização, utilizando balança de precisão de $0,0001 \mathrm{~g}$, conforme Equação (3). O resultado do ensaio para cada mistura representa a média de determinações realizadas em 10 agregados.

$$
P M=\frac{M_{d}-M_{s}}{M_{d}} \times 100
$$

onde,

$P M$ é perda de massa do agregado (\%);

$M_{S}$ é a massa do agregado na condição sinterizada (g); e,

$M_{d}$ é a massa do agregado na condição seca ( $\left.\mathrm{g}\right)$.

A massa específica aparente dos grãos (Equação (4)) e absorção de água (Equação (5)) foram determinadas seguindo a ABNT 6465 [13]. A ACI 213 [14] aponta que o módulo de elasticidade do concreto é uma função do módulo elasticidade de seus constituintes e apresenta uma relação entre o módulo de elasticidade dos agregados leves e sua massa específica aparente. Essa relação é expressa pela Equação (6).

$$
\begin{aligned}
& \rho_{a p(s)}=\frac{M_{s}}{M_{s a t}-M_{i}} \times \rho_{w} \\
& A_{a}=\frac{M_{s a t}-M_{s}}{M_{s}} \times 100 \\
& E_{c}=0,008 \times \rho_{a p(s)^{2}}
\end{aligned}
$$

onde,

$\rho_{a p(s)}$ é a massa específica aparente dos grãos $\left(\mathrm{g} / \mathrm{cm}^{3}\right)$;

$A_{a}$ é a absorção de água, em porcentagem da massa de material seco;

$M_{S}$ é a massa da amostra seca $(\mathrm{g})$;

$M_{\text {sat }}$ é a massa da amostra saturada, superficialmente seca $(\mathrm{g})$;

$M_{i}$ é a massa da amostra totalmente imersa em água (g);

$\rho_{w}$ é a massa específica da água $\left(\mathrm{g} / \mathrm{cm}^{3}\right)$ à temperatura $\mathrm{T}\left({ }^{\circ} \mathrm{C}\right)$ do ensaio; e,

$E_{c}$ é o módulo de deformação $(\mathrm{MPa})$.

A massa unitária de um agregado é medida pela razão entre a massa de determinada amostra e o volume ocupado pela mesma, incluindo-se os vazios entre os grãos, calculada conforme descrito na Equação (7). Os agregados foram ensaiados na condição triturada, de modo a reduzir os vazios entre os grãos. Após triturados os agregados apresentam valores maiores de massa unitária, representando a pior condição dentro das possibilidades para realização do presente ensaio. Ressaltando-se ainda que o presente ensaio tem como principal objetivo estabelecer um fator comparativo entre as amostras analisadas. 


$$
M U T=\frac{M_{t}}{V_{t}}
$$

Onde,

MUT é a massa unitária do agregado triturado $\left(\mathrm{g} / \mathrm{cm}^{3}\right)$;

$M_{t}$ é a massa da amostra do agregado triturado $(\mathrm{g}) ; \mathrm{e}$,

$V_{t}$ é o volume ocupado pela a amostra do agregado triturado na proveta graduada $\left(\mathrm{cm}^{3}\right)$.

O ensaio de resistência ao esmagamento baseou-se nos trabalhos de LI et al. [15] que buscou analisar a resistência de grãos individualmente, e, HIRAMATSU e OKA [16] que desenvolveram uma solução matemática para estimar a resistência à tração de esferas submetidas a carregamento diametral (Equação (8)). Utilizou-se uma prensa de bancada modelo ZwichLine Z2.5 com capacidade de carga máxima de 2,5kN e carga mínima de $1 \mathrm{~N}$, com descida da célula de carga a velocidade de $0,1 \mathrm{~mm} / \mathrm{min}$. O resultado foi obtido a partir da média aritmética de 5 determinações.

$$
\sigma_{M} \approx \frac{2,8 \times P}{\pi \times d^{2}}
$$

Onde,

$\sigma_{M}$ é a resistência à tração $(\mathrm{MPa})$;

$P$ é a carga crítica aplicada $(\mathrm{N}) ; \mathrm{e}$,

$d$ é a distância entre os pontos de carregamento ( $\mathrm{mm}$ ).

Para a análise visual, os agregados produzidos foram fotografados na condição íntegra e também triturada possibilitando observar o interior e exterior dos agregados, em cada temperatura de sinterização. Foram fotografados também os agregados na condição verde, ou seja, antes da queima. Para a execução das fotografias, utilizou-se folhas e cartolinas brancas para o fundo das fotos, régua para referência de tamanho e para a iluminação foram utilizadas duas luminárias de LED com luz branca. A câmera utilizada é do modelo COOLPIX P520 apoiada em um tripé modelo WF3716.

A caracterização morfológica foi realizada através da microscopia eletrônica de varredura (MEV) utilizando equipamento modelo VEGA3-LMU TESCAN, operado com energia de feixe de elétrons de $20 \mathrm{kV}$ e ampliações entre 19x e 450x.A preparação da amostra se deu na escolha de fragmentos hemisféricos do agregado que apresentou melhores resultados em relação as propriedades anteriormente descritas, rompido no ensaio de resistência ao esmagamento. As amostras foram depositadas no porta amostras sobre uma fita adesiva de carbono que foi levada até o topo da amostra, a fim de aumentar a condutividade elétrica, concentrando a maior parte dos elétrons no topo da amostra, evitando a dispersão dos mesmos e melhorando a qualidade da imagem obtida. As amostras também foram metalizadas pela pulverização de plasma de ouro em um equipamento QUORUM Q150R ES com tempo de exposição de 60s.

\section{RESULTADOS}

\subsection{Caracterização dos precursores}

A Tabela 2 apresenta os resultados de caracterização física dos precursores, e, a Figura 2 apresenta o difratograma de raios-x da ARG-B, onde observa-se que as fases cristalinas presentes na amostra são dos argilominerais Caulinita e Haloisita, além da presença de Quartzo. O resultado da análise mineralógica reforça a composição química apresentada na Tabela 3, com a presença predominante de óxidos de silício e alumínio.

Por se tratar de uma argila branca, proveniente do mineral Caulim, já era esperado que sua composição mineralógica apresentasse silicatos hidratados de alumínio, em especial a caulinita e haloisita por serem os mais frequentes, como por exemplo o Caulim utilizado por PINHEIRO [17] da mesma região de origem da ARG-B e apresenta mineralogia semelhante. 
Tabela 2: Resumo dos relatórios de granulometria à laser, BET, finura, massa específica e massa unitária.

\begin{tabular}{c|c|c}
\hline ENSAIOS/ANÁLISES & ARG-B & RGM \\
\hline Diâmetro a $10 \%-\mu \mathrm{m}$ & 0,94 & 0,49 \\
\hline Diâmetro a $50 \%-\mu \mathrm{m}$ & 4,21 & 4,57 \\
\hline Diâmetro a $90 \%-\mu \mathrm{m}$ & 24,76 & 38,93 \\
\hline Diâmetro médio $-\mu \mathrm{m}$ & 9,23 & 12,61 \\
\hline Área superficial específica BET $-\mathrm{m}^{2} / \mathrm{g}$ & 8,92 & 5,10 \\
\hline Volume total de poros $(\mathrm{BET})-\mathrm{cm}^{3} / \mathrm{g}$ & $1,70 \times 10-2$ & $1,01 \times 10-^{2}$ \\
\hline Finura - Massa retida na \#0,075mm - \% & 0,40 & 2,20 \\
\hline Massa específica $-\mathrm{g} / \mathrm{cm}^{3}$ & 2,44 & 2,71 \\
\hline Massa unitária $-\mathrm{g} / \mathrm{cm}^{3}$ & 0,69 & 0,76 \\
\hline
\end{tabular}

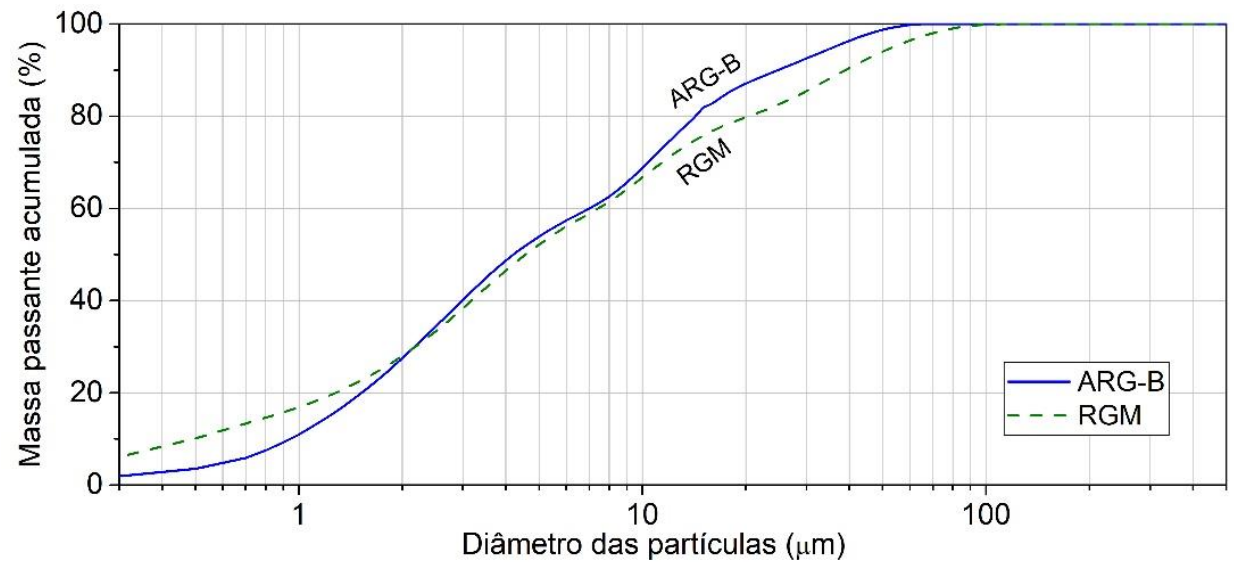

Figura 1: Curvas granulométricas da ARG-B e do RGM.

Tabela 3: Composição química dos precursores (FRX).

\begin{tabular}{c|c|c|c|c|c|c|c|c|c|c}
\hline & $\mathbf{S i O}_{2}$ & $\mathbf{A l}_{2} \mathbf{O}_{3}$ & $\mathbf{F e}_{2} \mathbf{O}_{3}$ & $\mathbf{N a}_{2} \mathbf{O}$ & $\mathbf{K}_{\mathbf{2}} \mathbf{O}$ & $\mathbf{C a O}$ & $\mathbf{M g O}$ & $\mathbf{T i O}_{2}$ & $\mathbf{\Sigma O F}$ & $\mathbf{S i O}_{2} / \mathbf{\Sigma O F}$ \\
\hline ARG-B & 55,80 & 41,95 & 0,71 & 0,24 & 0,88 & 0,02 & 0,15 & 0,05 & 2,00 & 27,87 \\
\hline RGM & 39,01 & 7,00 & 5,51 & 2,21 & 0,56 & 29,44 & 13,71 & 1,60 & 51,43 & 0,76 \\
\hline
\end{tabular}
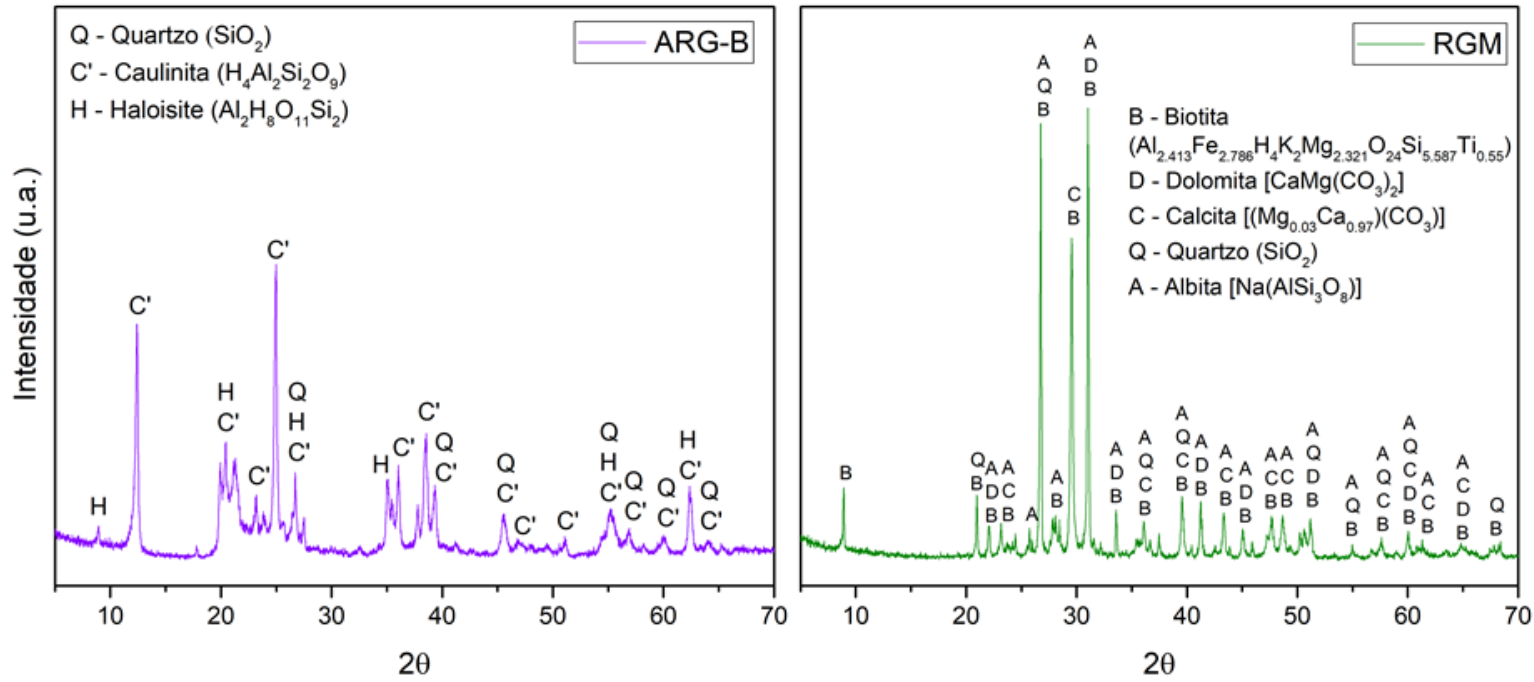

Figura 2: Difratogramas de raios-X (DRX) da ARG e do RGM. 
O argilomineral Caulinita e o Quartzo também estão presentes na argila utilizada por SOLTAN et al. [6], cujo trabalho embasou a produção das composições com RGM adotadas no presente trabalho, porém, os outros minerais presentes, a albita $\left(\mathrm{NaAlSi}_{3} \mathrm{O}_{8}\right)$ e a Montmorillonita $\left(\mathrm{Na}_{0,2} \mathrm{Ca}_{0,1} \mathrm{Al} 2 \mathrm{Si} 4 \mathrm{O} 10(\mathrm{OH})_{2}\left(\mathrm{H}_{2} \mathrm{O}\right)_{10}\right)$, não foram identificadas na ARG-B, provavelmente devido a sua alta pureza.

O RGM estudado na presente pesquisa apresenta fases de Biotita, Dolomita, Calcita, Albita e Quartzo (Figura 2), o que se mostra coerente com os resultados obtidos através da análise química (FRX), com a predominância dos óxidos de silício, cálcio e magnésio, com teores entre $14 \%$ e 39\% e a presença de óxidos de alumínio, ferro, sódio e titânio em teores mais baixos, entre 2\% e 7\% (Tabela 3).

No estudo de SOLTAN et al. [6] o RGM também apresenta os minerais quartzo $\left(\mathrm{SiO}_{2}\right)$, albita $(\mathrm{NaAl}-$ $\left.\mathrm{Si}_{3} \mathrm{O}_{8}\right)$ e biotita $\left(\mathrm{K}(\mathrm{Mg}, \mathrm{Fe})_{3} \mathrm{AlSi}_{3} \mathrm{O}_{10}(\mathrm{OH}, \mathrm{F})\right)$, porém, também apresenta fases de hornblenda $\left(\mathrm{Ca}_{2} \mathrm{Mg}_{4} \mathrm{AlFeSi} 7 \mathrm{AlO}_{22}(\mathrm{OH})_{2}\right)$ e microclínio $\left(\mathrm{KAlSi}_{3} \mathrm{O}_{8}\right)$, que não foram identificados no presente estudo. $\mathrm{O}$ que também acompanhou as diferenças observadas na composição química desses materiais, visto que o RGM do autor [6] apresenta $71 \%$ de $\mathrm{SiO}_{2}, 13 \%$ de $\mathrm{Al}_{2} \mathrm{O}_{3}, 5 \%$ de $\mathrm{Fe}_{2} \mathrm{O}_{3}$ e $\mathrm{K}_{2} \mathrm{O}, 3 \%$ de $\mathrm{Na}_{2} \mathrm{O}$, além de óxidos de cálcio, magnésio e titânio em teores inferiores a $2 \%$.

A análise térmica dos precursores é apresentada na Figura 3, verifica-se que a argila branca (ARG-B) mostra o comportamento típico de uma argila refratária rica em sílica e alumina, confirmando a composição química e mineralógica já apresentada, muito semelhante ao apresentado por BRAGANÇA e BERGMANN [18], onde a perda de massa até $100^{\circ} \mathrm{C}$ é atribuída a liberação de água adsorvida (evento endotérmico), a queima das substâncias orgânicas ocorre até cerca de $400^{\circ} \mathrm{C}$ em um pico exotérmico, e, aproximadamente a $550^{\circ} \mathrm{C}$ ocorre a desidroxilação da caulinita formando a metacaulinita $\left(\mathrm{Al}_{2} \mathrm{O}_{3} \cdot 2 \mathrm{SiO}_{2}\right)$ em uma reação endotérmica. O registro na curva DTA da ARG-B, possivelmente referente a esse último evento, ocorre a $516^{\circ} \mathrm{C}$.

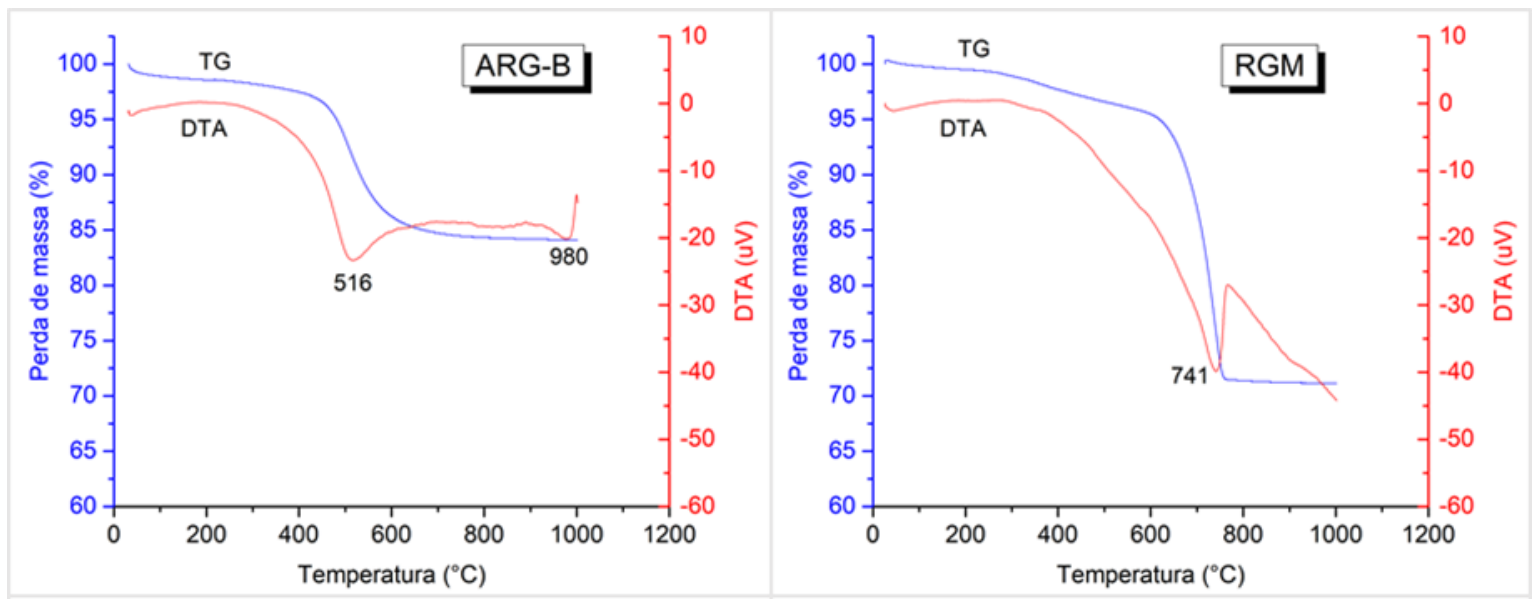

Figura 3: Análise térmica por termogravimetria (TG) e análise térmica diferencial (DTA) da ARG e do RGM.

A ARG-B apresenta uma perda de massa a $1000^{\circ} \mathrm{C}$ de $16 \%$, e pela análise realizada acima, infere-se que possivelmente o principal evento responsável pela perda de massa da argila é a desidroxilação da caulinita e que a argila possui baixo teor de matéria orgânica.

Já o RGM apresenta uma perda de massa a $1000^{\circ} \mathrm{C}$ de $29 \%$, onde a principal perda de massa está associada a um evento endotérmico a $741^{\circ} \mathrm{C}$. Suas curvas TG e DTA são bastante similares ao apresentado por MORENO-MAROTO et al. [8] que também utilizou RGM e suas curvas apresentam uma grande perda de massa associada a um evento endotérmico a $708^{\circ} \mathrm{C}$ que foi associado a decomposição da calcita em $\mathrm{CO}_{2}$.

\section{2 Índice de encolhimento}

$\mathrm{O}$ índice de encolhimento foi o primeiro ensaio realizado nos agregados e apresenta como resposta o índice de retração do agregado moldado após secagem. A propriedade é investigada na indústria produtora de peças cerâmicas pois verifica as deformações das peças ao longo do processo produtivo, diagnosticando deformações que possam desaprovar as peças além de ser importante para estabelecer o desenho dos moldes. Dessa forma o índice de encolhimento foi observado nesta pesquisa com intuito de avaliar deformações excessivas das misturas, considerando que se pretenda obter agregados de determinada granulometria.

O teor de sílica livre e matéria orgânica influenciam na retração das peças, enquanto um maior teor de sílica reduz a plasticidade da argila e também diminui a retração das peças, um maior teor de matéria orgâni- 
ca além de gerar maior retração e fissuras nas peças ela também pode resultar em diferenças de coloração em um mesmo componente [19].

A Figura 4 apresenta os resultados de índice de encolhimento dos agregados produzidos, onde pode ser observado que os teores de 60\% a 100\% de RGM apresentam índices de encolhimento próximos entre si e inferiores em relação as misturas com $50 \%$ e $100 \%$ de ARG-B, ou seja, a inclusão do resíduo resultou em menores índices de retração, porém, a diferença entre as misturas não é excessiva.

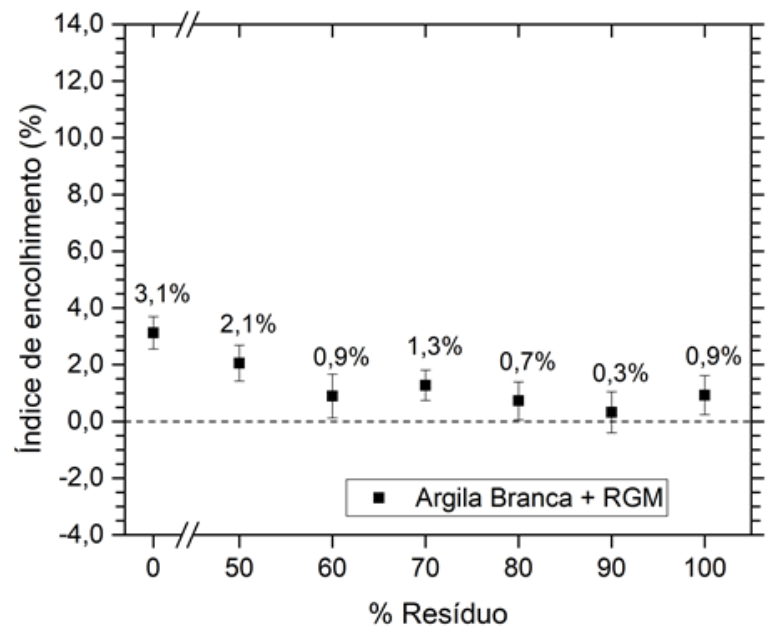

Figura 4: índice de encolhimento realizado nos agregados das 7 composições estudadas.

\subsection{Análise visual}

Ao todo foram registradas 117 fotografias que estão disponíveis através do link: https://drive.google.com/drive/folders/1tSI4FYOGf7ce0UgxAV6AMvbLZ43A131T?usp=sharing. As misturas com teores de $80 \%, 90 \%$ e $100 \%$ de RGM, quando submetidos a temperaturas até $1000^{\circ} \mathrm{C}, 1050^{\circ} \mathrm{C}$ e $1100^{\circ} \mathrm{C}$, respectivamente, esfarelaram, pois, o tratamento térmico realizado foi insuficiente para que as transformações de fase resultassem em produtos resistentes.

Mas, em geral, essas composições não sofrem alterações significativas de formato, textura ou coloração até a temperatura de $1200^{\circ} \mathrm{C}$; a exceção é a mistura RGM- $80 \%$ que a $1200^{\circ} \mathrm{C}$ apresentou a formação de uma casca brilhosa de baixa porosidade e de cor escura na parte de cima da amostra, já a parte do agregado que ficou mais próxima a placa refratária permaneceu mais clara. Internamente é possível observar a formação de grandes poros.

Na mesma linha a mistura RGM-70\% apresentou a formação da casca vítrea na temperatura de $1213^{\circ} \mathrm{C}$, porém de forma mais homogênea que a mistura RGM-80\%, mantendo maior esfericidade e produzindo poros de tamanhos e distribuição mais uniforme. Ressaltando que a estrutura de poros ideal para o agregado leve compreende um alto volume de poros de tamanho e distribuição uniformes [20].

Os agregados com $100 \%$ de resíduo e $100 \%$ de argila não derreteram mesmo sob temperaturas de até $1263^{\circ} \mathrm{C}$, mas a sinergia desses apresentou temperaturas onde ocorreu o derretimento (D), formação de casca de baixa porosidade $(\mathrm{C})$ ou mudança visual significativa (MV) referente a coloração, textura e formato. Um resumo dessas mudanças é apresentado na Tabela 4.

Na Figura 5 é apresentado uma compilação com algumas das imagens registradas, apresentado os agregados verdes (antes da sinterização) e após sinterização à $1200^{\circ} \mathrm{C}$, também são mostrados os agregados sinterizados nas respectivas temperaturas de queima limite, ou seja, a temperatura anterior a qual ocorre o derretimento do agregado. Os agregados sinterizados são apresentados na condição íntegra e triturada.

Tabela 4: Resumo das mudanças visuais significativas apresentada pelos agregados.

\begin{tabular}{c|c|c|c|c|c|c|c|c|c|c}
\hline & $1000^{\circ} \mathbf{C}$ & $1050^{\circ} \mathbf{C}$ & $1100^{\circ} \mathbf{C}$ & $1150^{\circ} \mathbf{C}$ & $1200^{\circ} \mathbf{C}$ & $1213^{\circ} \mathbf{C}$ & $1^{225^{\circ} \mathbf{C}}$ & $1^{238^{\circ} \mathbf{C}}$ & $1^{250^{\circ} \mathbf{C}}$ & $1^{263^{\circ} \mathbf{C}}$ \\
\hline ARG-B & SA & SA & SA & SA & SA & SA & SA & SA & SA & SA \\
\hline RGM-50 $\%$ & SA & SA & SA & SA & SA & SA & SA & MV & MV & D \\
\hline RGM-60 $\%$ & SA & SA & SA & SA & SA & MV & MV & D & - & - \\
\hline RGM-70 $\%$ & SA & SA & SA & SA & MV & C & D & - & - & - \\
\hline
\end{tabular}




\begin{tabular}{c|c|c|c|c|c|c|c|c|c|c}
\hline RGM-80\% & E & SA & SA & SA & C & D & - & - & - & - \\
\hline RGM-90\% & E & E & SA & SA & MV & MV & C & D & - & - \\
\hline RGM-100\% & E & E & E & SA & MV & MV & MV & MV & MV & MV \\
\hline
\end{tabular}

E - Esfarelamento; D - Derretimento; C - Formação da casca de baixa porosidade; MV - Mudança visual significativa; e, $\mathrm{SA}$ - Sem alteração significativa.

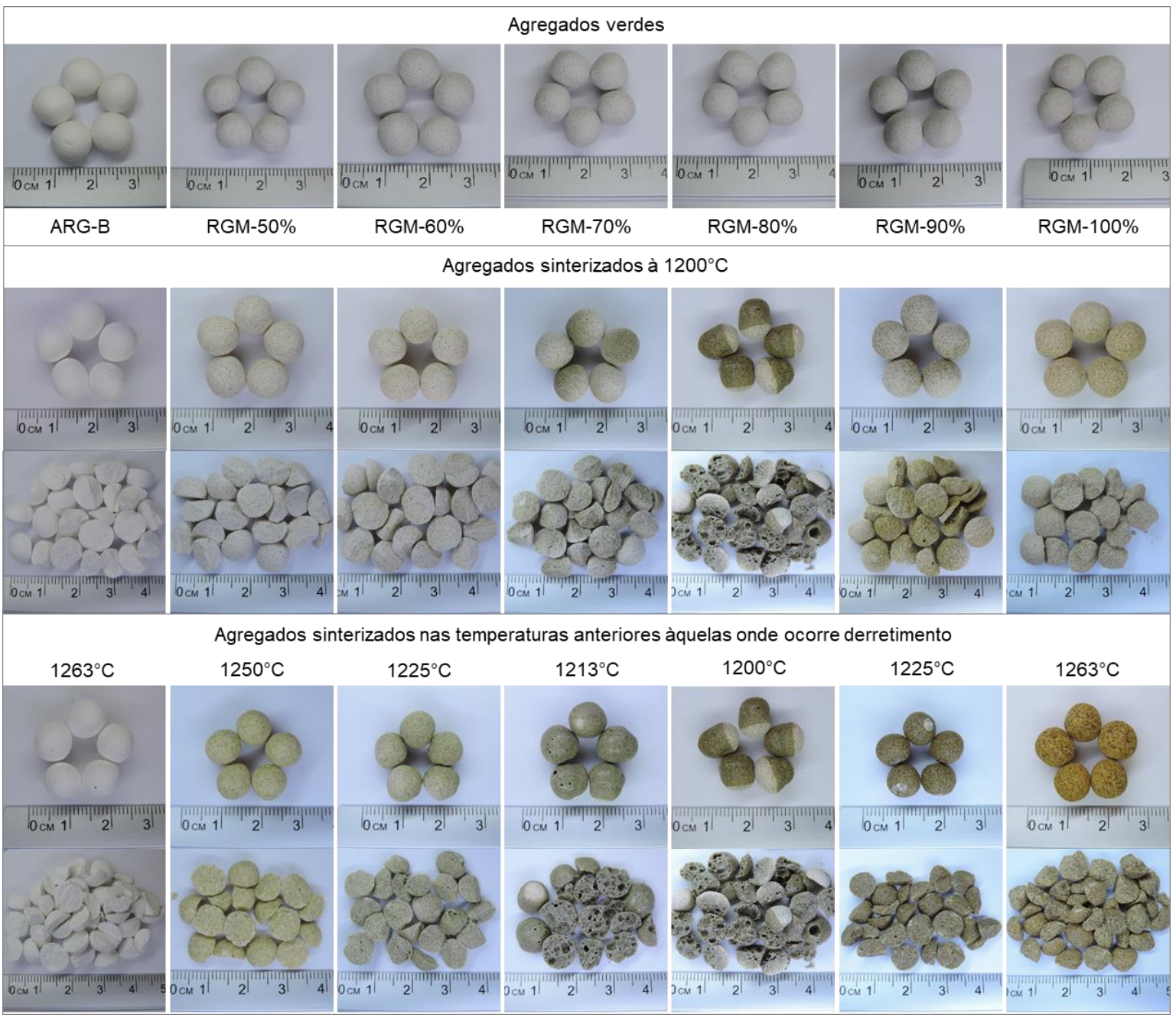

Figura 5: principais imagens registradas na análise visual.

\subsection{Massa específica aparente e absorção de água}

A Figura 6 apresenta os resultados dos ensaios de massa específica aparente e absorção de água, onde pode ser observado quais agregados atendem a definição de agregado leve com massa específica aparente inferior à $2,00 \mathrm{~g} / \mathrm{cm}^{3}[2]$.

Quanto a absorção de água, foi observado que os agregados comercializados no mundo, em sua maioria apresentam absorção inferior a 20\% [20]; corroborando com NEVILLE [21], que aponta que a absorção de agregados leves varia entre $5 \%$ e $20 \%$, mas, para agregados de boa qualidade destinados ao uso em concreto estrutural, ela normalmente é inferior a $15 \%$.

Nesse contexto, verifica-se na Figura 6 que todos os agregados, quando calcinados até $1200^{\circ} \mathrm{C}$ atendem ao parâmetro de massa específica aparente [2], porém, apresentam, em geral, valores de absorção de água superiores a $20 \%$. Nota-se também que o acréscimo de temperatura diminui a absorção de água de todas as misturas, porém, para algumas misturas essa diminuição acompanhou um aumento de massa específica aparente, ultrapassando o limite superior definido [2]. 


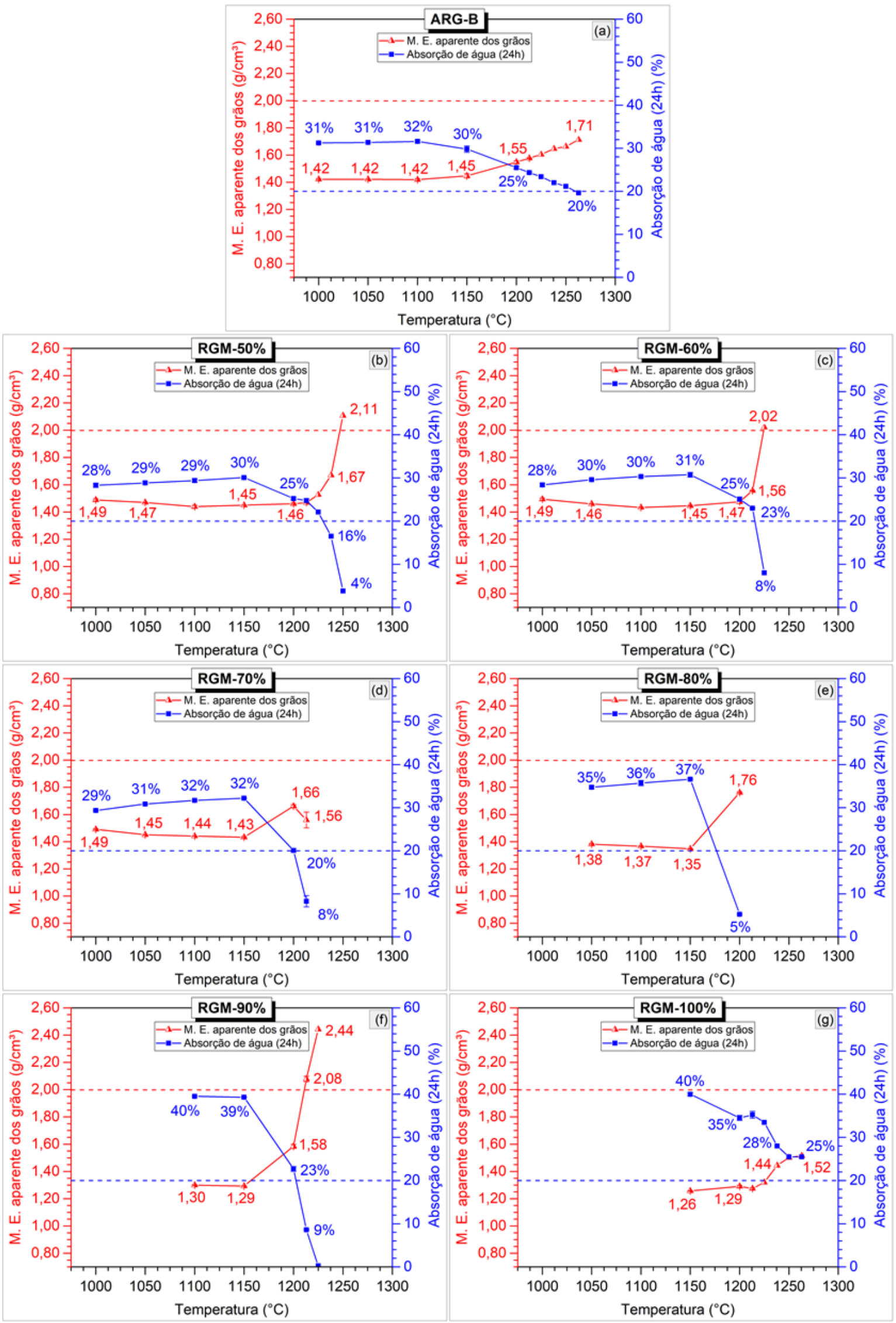

Figura 6: Resultados dos ensaios de massa específica aparente e absorção de água (24h) dos agregados produzidos. 
Nesse sentido, na Tabela 5 é apresentado um resumo das misturas que atendem simultaneamente os parâmetros de massa específica aparente e absorção de água.

Considerando os resultados apresentados, o RGM-70\% sinterizado à $1213^{\circ} \mathrm{C}$ apresenta o menor valor de massa específica aparente entre as composições, de $1,56 \mathrm{~g} / \mathrm{cm}^{3}$, e, assim como as misturas RGM-60\% a $1225^{\circ} \mathrm{C}$ e $\mathrm{RGM}-80 \%$ a $1200^{\circ} \mathrm{C}$ possui absorção de água inferior a $15 \%$, compatível com agregados de boa qualidade utilizados em concretos estruturais [21].

Tabela 5: Resultados de massa específica aparente e absorção de água dos agregados que atendem aos parâmetros de agregado leve.

\begin{tabular}{c|c|c|c}
\hline MISTURA & TEMPERATURA & MASSA ESPECÍFICA APARENTE & ABSORÇÃO DE ÁGUA \\
\hline ARG-B & $1263^{\circ} \mathrm{C}$ & $1,71 \mathrm{~g} / \mathrm{cm}^{3}$ & $20 \%$ \\
\hline RGM-50\% & $1238^{\circ} \mathrm{C}$ & $1,67 \mathrm{~g} / \mathrm{cm}^{3}$ & $16 \%$ \\
\hline RGM-60\% & $1225^{\circ} \mathrm{C}$ & $2,02 \mathrm{~g} / \mathrm{cm}^{3}$ & $8 \%$ \\
\hline \multirow{2}{*}{ RGM-70\% } & $1200^{\circ} \mathrm{C}$ & $1,66 \mathrm{~g} / \mathrm{cm}^{3}$ & $20 \%$ \\
\cline { 2 - 4 } & $1213^{\circ} \mathrm{C}$ & $1,56 \mathrm{~g} / \mathrm{cm}^{3}$ & $8 \%$ \\
\hline RGM-80\% & $1200^{\circ} \mathrm{C}$ & $1,76 \mathrm{~g} / \mathrm{cm}^{3}$ & $5 \%$ \\
\hline
\end{tabular}

\subsection{Módulo de deformação}

A Figura 7 apresenta os valores de módulo de deformação dos agregados, onde é possível verificar que, com exceção dos agregados das misturas RGM- $90 \%$ a $1225^{\circ} \mathrm{C}$ e o RGM-50\% a $1250^{\circ} \mathrm{C}$, todos os agregados produzidos se apresentam dentro do intervalo de valores de módulo de elasticidade dos agregados leves comercializados catalogados por ROSSIGNOLO e AGNESINI [22], entre 3 e 35GPa.

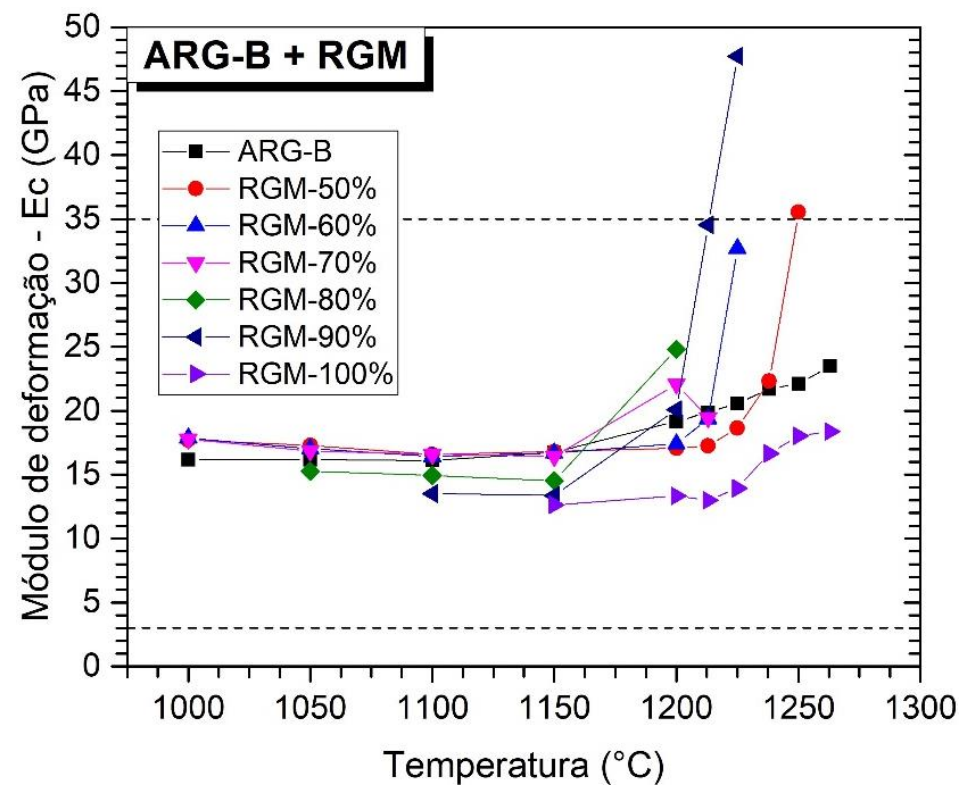

Figura 7: Módulo de deformação dos agregados produzidos.

\subsection{Resistência ao esmagamento}

A Figura 8 apresenta os resultados de resistência à tração dos agregados. Foram realizadas rupturas nas temperaturas de $1150^{\circ} \mathrm{C}, 1200^{\circ} \mathrm{C}$ e $1225^{\circ} \mathrm{C}$ e a linha tracejada ressalta o valor $2,23 \mathrm{MPa}$ referente ao resultado do presente ensaio realizado no agregado leve artificial comercial. Dessa forma, observa-se que as resistências alcançadas pelos agregados produzidos com argila branca e o resíduo RGM em geral são significativamente mais altas que a referência.

Ressalta-se que não foi possível aferir a resistência ao esmagamento da mistura RGM- $90 \%$ à $1225^{\circ} \mathrm{C}$, local marcado com asterisco $\left(^{*}\right)$, pois, o valor de carga excedeu o limite do equipamento utilizado, porém, foi possível estimar que o valor de resistência à tração para este é superior a $31 \mathrm{MPa}$. 


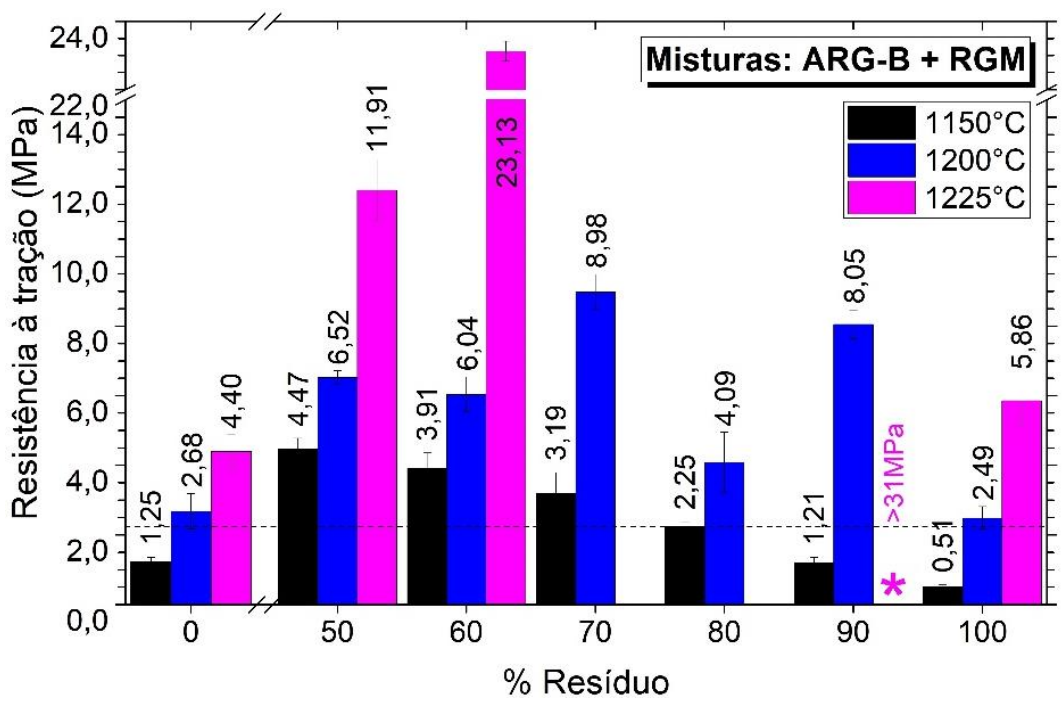

Figura 8: Resistência à tração das amostras as quais foi realizado ensaio de resistência ao esmagamento.

Considerando os resultados apresentados é possível verificar a influência do aumento de temperatura no ganho de resistência, evidenciada em todas as misturas. Foi confirmado que misturas que contêm maior teor de sílica $\left(\mathrm{SiO}_{2}\right)$ e alumina $\left(\mathrm{Al}_{2} \mathrm{O}_{3}\right)$, responsáveis pela formação da fase vítrea, apresentam maiores resistências em relação a composições com teores reduzidos [23]. Além do teor de $\mathrm{SiO}_{2}$ e $\mathrm{Al}_{2} \mathrm{O}_{3}$, o teor de óxidos fundentes (OF) exerce grande influência na resistência dos produtos cerâmicos. O teor de OF afeta as relações de equilíbrio entre a sílica e alumina e diminuem consideravelmente a temperatura eutética, além de alterarem a composição [24].

\subsection{Massa unitária}

A Figura 9 apresenta a massa unitária dos agregados, juntamente com os respectivos valores da relação $\mathrm{SiO}_{2} / \Sigma \mathrm{OF}$. A linha de referência nos gráficos de massa unitária estabelece o limite superior de $0,88 \mathrm{~g} / \mathrm{cm}^{3}$ para agregados graúdos leves [1]. Já quando à relação $\mathrm{SiO}_{2} / \Sigma \mathrm{OF}$, as linhas de referência marcam o intervalo de 1,00 a 3,85, referente as relações de $\mathrm{SiO}_{2} / \Sigma \mathrm{OF}$ de agregados leves comercializados [25,26] e produzidos por autores anteriores $[6,27,28,29]$. 

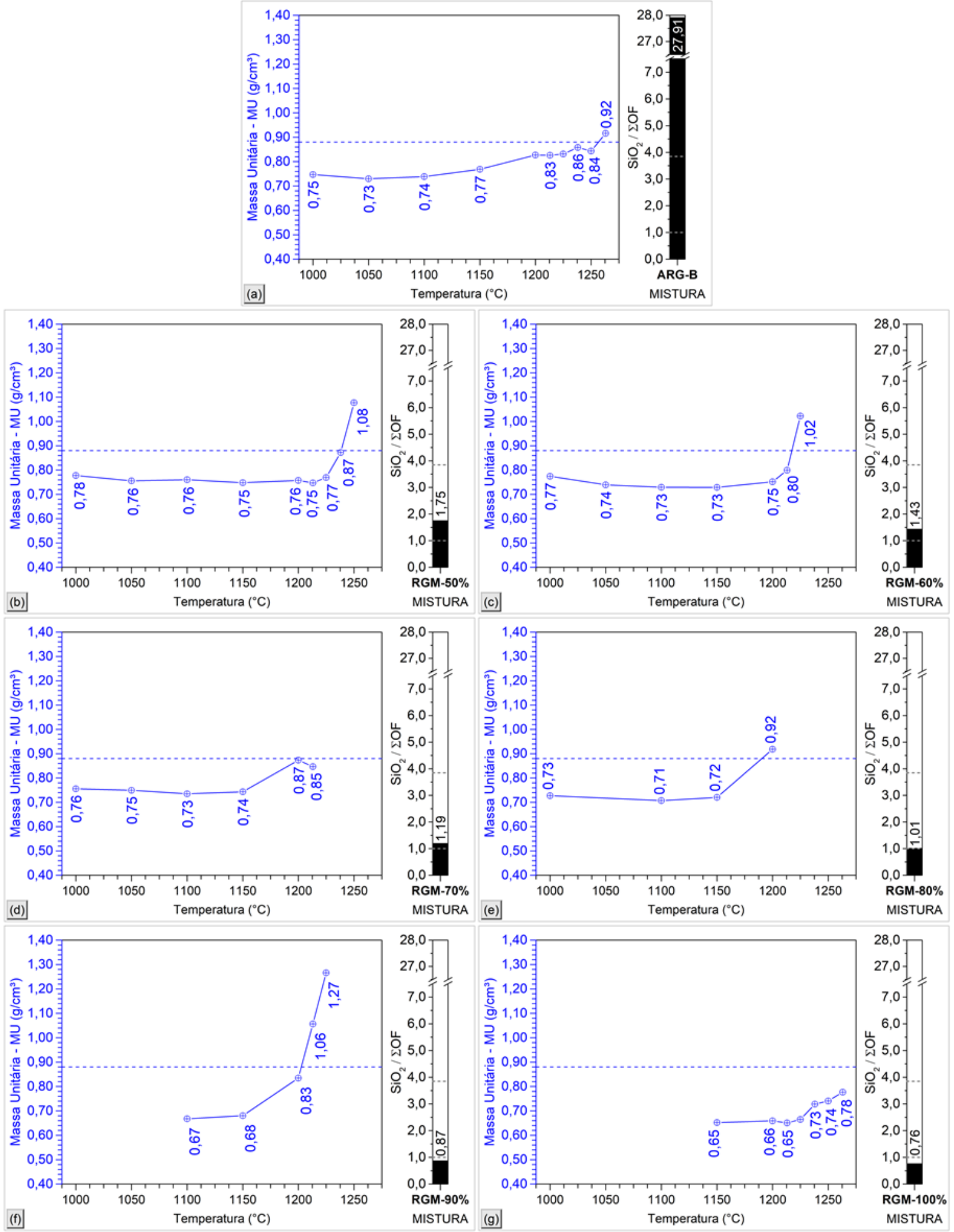

Figura 9: Resultados de massa unitária dos agregados triturados.

Observa-se na Figura 9 que a propriedade de massa unitária acompanhou a tendência já observada na análise da massa específica aparente, em que o aumento da temperatura provoca o aumento dos valores de massa unitária. Outrossim, todos agregados das misturas RGM-70\% e RGM-100\% estão abaixo do limite de $0,88 \mathrm{~g} / \mathrm{cm}^{3}$. Verifica-se também que, quanto aos melhores resultados observados na propriedade de massa específica e absorção de água (Tabela 5) apenas os agregados RGM-70\% a $1200^{\circ} \mathrm{C}$ e $1213^{\circ} \mathrm{C}$ e RGM-50\% a $1238^{\circ} \mathrm{C}$ possuem valores de massa unitária inferiores a $0,88 \mathrm{~g} / \mathrm{cm}^{3}$. Ressaltando que os mesmos possuem valores de relação $\mathrm{SiO}_{2} / \Sigma \mathrm{OF}$ também dentro do intervalo de 1,00 a 3,85, e, o melhor resultado observado foi o da mistura RGM- $70 \%$ a $1213^{\circ} \mathrm{C}$. 


\section{8 Índice de inchaço e perda de massa}

O índice de inchaço e perda de massa dos agregados são apresentados na Figura 10, onde é possível observar que em geral os agregados não apresentaram inchaço e que o incremento de temperatura provocou maior retração nos agregados. A maior retração, ou seja, o menor valor de índice de inchaço observado foi de $17,8 \%$, no agregado RGM-90\% a $1225^{\circ} \mathrm{C}$.

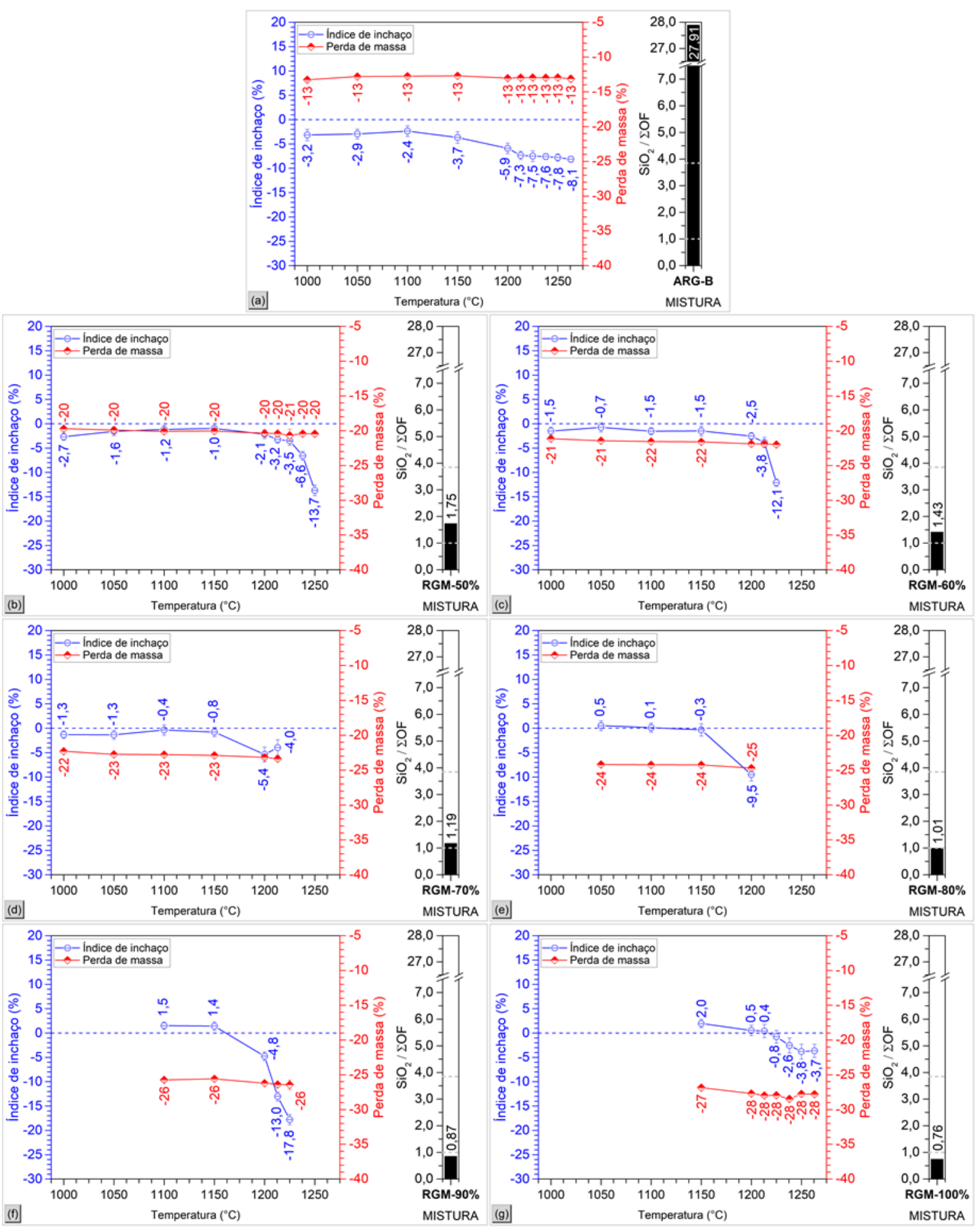

Figura 10: Resultados dos ensaios de índice de inchaço e perda de massa.

Analisando os melhores resultados apresentados na propriedade anterior (massa unitária), destaca-se que entre as misturas RGM-70\% a $1200^{\circ} \mathrm{C}$ e a $1213^{\circ} \mathrm{C}$ e RGM-50\% a $1238^{\circ} \mathrm{C}$, o maior índice de inchaço foi observado na mistura RGM-70\% a $1213^{\circ} \mathrm{C}$, mesmo com índice de inchaço negativo $(-4,0 \%)$, esses agregados 
retraíram menos em relação aos demais. Observou-se também que os agregados com 80\%, 90\% e 100\% de RGM apresentaram um sutil inchaço nas temperaturas inferiores a $1150^{\circ} \mathrm{C}$, com valores entre $0,1 \mathrm{e} 2,0 \%$, porém, esses agregados não registraram bons resultados quanto as demais propriedades supra analisadas.

Quanto a perda de massa, verifica-se que as menores perdas são observadas na mistura com argila branca pura (ARG-B), com 13\%, e que o incremento do teor de RGM nas misturas aumenta a perda de massa a até $28 \%$, observada na mistura RGM-100\%. Nota-se também que o incremento de temperatura a partir de $1000^{\circ} \mathrm{C}$ não alterou a perda de massa nas misturas, que se manteve praticamente constante $( \pm 1 \%)$.

Nesse contexto, a perda de massa foi provocada em temperaturas inferiores à $1000^{\circ} \mathrm{C}$, e, possivelmente está relacionada com as transformações observadas na análise de TG e DTA, onde a perda de massa registrada para os precursores ARG-B e RGM foram atribuídas principalmente à degradação da caulinita e calcita, respectivamente.

\subsection{Microscopia de varredura eletrônica (MEV)}

Considerando as demais propriedades supra analisadas, a análise morfológica por MEV foi realizada no agregado de melhor desempenho: RGM-70\% a $1213^{\circ} \mathrm{C}$. A visão geral desse (Figura 11) mostra que não houve diferença significativa entre o núcleo e a casca, onde a presença de poros maiores e menores ocorre ao longo de todo o agregado, muito embora o tamanho e a distribuição desses não seja homogênea; na parte inferior da imagem nota-se a concentração de poros menores, enquanto na parte superior nota-se a presença de poros significativamente maiores.
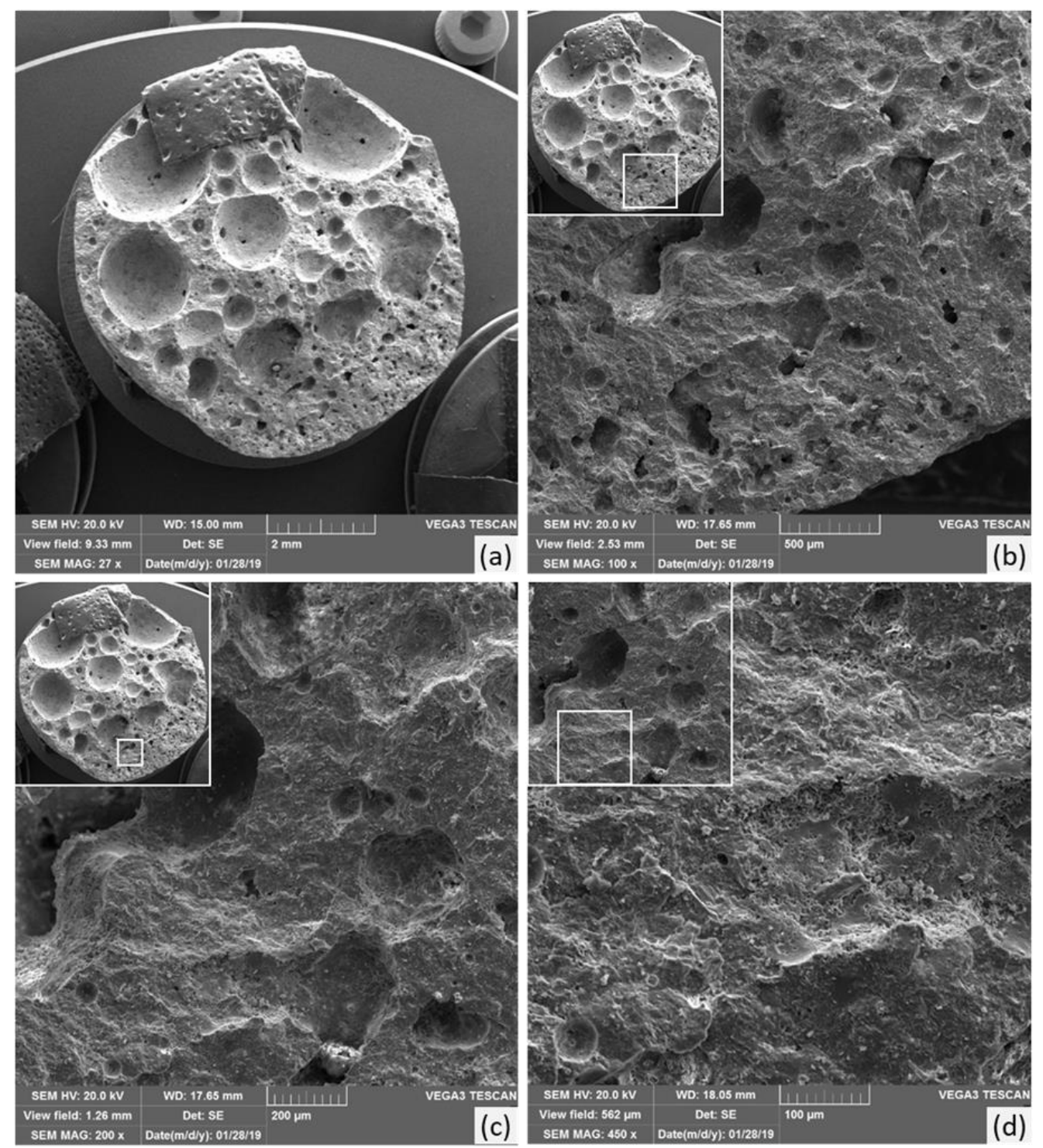

Figura 11: Imagens da microscopia por varredura eletrônica (MEV) realizada na mistura RGM-70\% a $1213^{\circ} \mathrm{C}$. 
A concentração de poros menores na parte inferior do agregado também ocorreu na mistura com $50 \%$ de RGM apresentada por SOLTAN et al. [6], onde os autores apontaram que a fluidez rápida da fase líquida menos viscosa da amostra impôs aos poros menores a movimentação do fundo do agregado para cima. E, que esse movimento é encorajado pela pressão exercida pela perda de massa. Esse mecanismo de fluidez da fase líquida explica os poros menos conectados da amostra, e que, a que a presença de poros de forma elíptica é resultado da possível fusão entre os poros menores e a expansão continuada das bolhas na fase líquida menos viscosa.

\section{CONCLUSÕES}

O presente trabalho teve como hipótese a possibilidade de produção de agregados leves a partir das matériasprimas regionais (Rio Grande do Norte/Nordeste/Brasil): argila branca (ARG-B) e o resíduo de corte de granitos e mármores (RGM). Com objetivo de estabelecer proporções ideais entre essas e diagnosticando temperaturas ótimas de sinterização para a produção de agregados leves graúdos regionais.

Foi possível produzir composições que atenderam simultaneamente aos requisitos prescritos para agregado graúdo leve, como massa específica aparente inferior a 2,00 g/ $\mathrm{cm}^{3}$, massa unitária inferior a 0,88 $\mathrm{g} / \mathrm{cm}^{3}$, e, absorção de água inferior $20 \%$.

Foram estudadas 7 misturas sinterizadas a temperaturas de $1000^{\circ} \mathrm{C}$ a $1263^{\circ} \mathrm{C}$, e, nesse processo foi observado que as misturas com alto teor de RGM apresentaram temperaturas nas quais os agregados esfarelaram ao serem manipulados, ou seja, apresentaram temperaturas mínimas de sinterização para resultar em produtos minimamente resistentes. Para as misturas RGM-80\%, RGM-90\% e RGM-100\% o esfarelamento ocorreu em temperaturas iguais ou inferiores a $1000^{\circ} \mathrm{C}, 1050^{\circ} \mathrm{C}$ e $1100^{\circ} \mathrm{C}$, respectivamente.

Não foi possível produzir agregados leves contendo apenas argila (ARG-B) ou apenas resíduo (RGM$100 \%$ ), porém, mostrou-se possível criar formulações com altos teores do resíduo que atendem as propriedades de massa específica aparente, absorção de água e massa unitária, mesmo sem que os mesmos apresentassem inchaço. Foram três formulações possíveis: RGM-50\% a $1238^{\circ} \mathrm{C}$ e RGM-70\% a $1200^{\circ} \mathrm{C}$ e a $1213^{\circ} \mathrm{C}$.

$\mathrm{O}$ agregado de melhor desempenho foi a mistura RGM-70\% sinterizada a $1213^{\circ} \mathrm{C}$ apresentando massa específica aparente de $1,56 \mathrm{~g} / \mathrm{cm}^{3}$, absorção água de $8 \%$ e massa unitária de $0,85 \mathrm{~g} / \mathrm{cm}^{3}$ valores que o classificam como agregado leve. Agregados da mesma mistura quando sinterizados a $1200^{\circ} \mathrm{C}$, também classificado como agregado leve, apresentam valores de resistência à tração da ordem de 9MPa.

Por fim, ressalta-se que o aumento de temperatura provocou aumento de resistência à tração dos agregados, e, todos os agregados produzidos na pesquisa, quando sinterizados à $1200^{\circ} \mathrm{C}$, apresentam resistência à tração significativamente altas, variando entre $2,49 \mathrm{MPa}$ e $8,98 \mathrm{MPa}$, sendo a mais baixa registrada para a composição RGM-100\%, e, a mais alta para a composição RGM-70\%.

\section{AGRADECIMENTOS}

Ao IFRN, UFRN, UFPB, UFCG, IFPB e ao Conselho Nacional de Desenvolvimento Científico e Tecnológico - CNPq.

\section{BIBLIOGRAFIA}

[1] AMERICAN SOCIETY FOR TESTING AND MATERIALS, ASTM C 331: Lightweight Aggregates for Concrete Masonry Units, West Conshohocken, 2010.

[2] EUROPEAN STANDARD, EN 13055: Lightweight aggregates, Brussels, 2016.

[3] GONZÁLEZ-CORROCHANO, B., ALONSO-AZCÁRATEA, J., RODRÍGUEZ, L., et al, "Valorization of washing aggregate sludge and sewage sludge for lightweight aggregates production", Construction And Building Materials, v. 116, pp. 252-262, jul. 2016. http://dx.doi.org/10.1016/j.conbuildmat.2016.04.095.

[4] CHEESEMAN, C., VIRDI, G., "Properties and microstructure of lightweight aggregate produced from sintered sewage sludge ash", Resources, Conservation and Recycling, v. 45, pp. 18-30, 2005, https://doi.org/10.1016/j.resconrec.2004.12.006.

[5] CLARKE, J. L., Structural lightweight aggregate concrete, CRC Press, 2002.

[6] SOLTAN, A. M. M., KAHL, W., EL-RAOOF, F. A., et al, "Lightweight aggregates from mixtures of granite wastes with clay", Journal of Cleaner Production, v. 117, pp. 139-149, 2016, https://doi.org/10.1016/j.jclepro.2016.01.017.

[7] MORENO-MAROTO, J. M, GONZÁLES-CORROCHANO, B., ALONSO-AZCÁRATE, J., et al, "Development of lightweight aggregates from stone cutting sludge, plastic wastes and sepiolite rejections for 
agricultural and environmental purposes", Journal of Environmental Management, v. 200, pp. 229-242, 2017, https://doi.org/10.1016/j.jenvman.2017.05.085.

[8] MORENO-MAROTO, J. M, GONZÁLES-CORROCHANO, B., ALONSO-AZCÁRATE, J., et al, "Manufacturing of lightweight aggregates with carbon fiber and mineral wastes", Cement and Concrete Composites, v. 83, pp. 335-348, 2017, https://doi.org/10.1016/j.cemconcomp.2017.08.001.

[9] ASSOCIAÇÃO BRASILEIRA DE NORMAS TÉCNICAS, NBR 11579: Cimento Portland - Determinação do indice de finura por meio da peneira 75 $\mu$ m ( $n^{\circ}$ 200), Rio de Janeiro, 2012.

[10] ASSOCIAÇÃO BRASILEIRA DE NORMAS TÉCNICAS, NBR 16605: Cimento Portland e outros materiais em pó - Determinação da massa específica, Rio de Janeiro, 2017.

[11] ASSOCIAÇÃO BRASILEIRA DE NORMAS TÉCNICAS, NBR 6459: Solo - Determinação do limite de liquidez, Rio de Janeiro, 2017.

[12] ASSOCIAÇÃO BRASILEIRA DE NORMAS TÉCNICAS, NBR 7180: Solo - Determinação do limite de plasticidade, Rio de Janeiro, 2016.

[13] ASSOCIAÇÃO BRASILEIRA DE NORMAS TÉCNICAS, NBR 6458: Grãos de pedregulho retidos na peneira de abertura 4,8 mm - Determinação da massa específica, da massa específica aparente e da absorção de água, Rio de Janeiro, 2016.

[14] AMERICAN CONCRETE INSTITUTE, ACI 213 R-03: Guide for Structural Lightweight Aggregate Concrete, Farmington Hills, 2003.

[15] LI, Y., WU, D., ZHANG, J., et al, "Measurement and statistics of single pellet mechanical strength of differently shaped catalysts", Powder Technology, v.113, n.1e2, pp. 176-184, Nov. 2000. https://doi.org/10.1016/S0032-5910(00)00231-X

[16] HIRAMATSU, Y., OKA, Y., "Determination of the tensile strength of rock by a compression test of an irregular test piece", International Journal of Rock Mechanics and Mining Sciences \& Geomechanics Abstracts, v.3, n.2, pp. 89-90, May, 1966, https://doi.org/10.1016/0148-9062(66)90002-7

[17] PINHEIRO, A. S., Produção de grês porcelanato a partir de matérias-primas do Rio Grande do Norte e queima a gás natural, Dissertação de M.Sc., Engenharia Mecânica, Universidade Federal do Rio Grande do Norte, Natal, RN, Brasil, 2006.

[18] BRAGANÇA, S. R., BERGMANN, C. P., Materiais Refratários e Abrasivos, In: ISAIA, G. C. (Ed.), Materiais de Construção Civil: e Princípios de Ciência e Engenharia dos Materiais, 2ed, São Paulo, IBRACON, cap. 20, pp. 619-656, 2010.

[19] KAZMIERCZAK, C. S., Produtos de Cerâmica Vermelha, In: ISAIA, G. C. (Ed.), Materiais de Construção Civil: e Princípios de Ciência e Engenharia dos Materiais, 2ed, São Paulo, IBRACON, 2010, cap. 18. pp. 565-588.

[20] AYATI, B., FERRÁNDIZ-MAS, V., NEWPORT, D., et al, "Use of clay in the manufacture of lightweight aggregate", Construction And Building Materials, v. 162, pp.124-131, fev. 2018, http://dx.doi.org/10.1016/j.conbuildmat.2017.12.018.

[21] NEVILLE, A M, Propriedades do concreto, 5. Ed, Porto Alegre, Bookman, 2016, 888 p, Tradução: Ruy Alberto Cremonini.

[22] ROSSIGNOLO, J. A, AGNESINI, M. V. C., Concreto leve estrutural, In: ISAIA, G. C. (Ed.), Concreto: ciência e tecnologia, São Paulo, IBRACON, Cap. 42, pp. 1531-1568, 2011.

[23] SANTIS, B. C, "Agregado leve de argila calcinada para uso em concreto estrutura: viabilidade da cerâmica vermelha do Estado de São Paulo", Dissertação de M.Sc. - Arquitetura e Urbanismo, Instituto de Arquitetura e Urbanismo de São Carlos, Universidade de São Paulo, Pirassununga, SP, Brasil, 2012.

[24] CASCUDO, O, CARASEK, H, HASPARYK, N. P., Microestrutura dos materiais cerâmicos, In: ISAIA, G. C. (Ed.), Materiais de Construção Civil: e Princípios de Ciência e Engenharia dos Materiais, 2ed, São Paulo: IBRACON, 2010, cap. 11, pp. 325-354.

[25] LYTAG®, https://www.aggregate.com/our-businesses/lytag, Acessado em janeiro de 2019.

[26] Cinexpan ${ }^{\circledR}$ - Indústria e Comércio de Argila Expandida Ltda, https://www.cinexpan.com.br, Acessado em janeiro de 2019.

[27] SANTIS, B. C., ROSSIGNOLO, J. A., "Avaliação da influência de agregados leves de argila calcinada no desempenho de concretos estruturais", Ambiente Construído, v. 14, n. 4, p. 21-32, out./dez. 2014. ISSN 1678-8621 Associação Nacional de Tecnologia do Ambiente Construído. 
[28] LAU, P. C., TEO, D. C. L., MANNAN, M. A., "Characteristics of lightweight aggregate produced from lime-treated sewage sludge and palm oil fuel ash", Construction and Building Materials, v. 152, pp. 558-567, 2017, https://doi.org/10.1016/j.conbuildmat.2017.07.022.

[29] HAN, M., HAN, D., SHIN, J., "Use of bottom ash and stone dust to make lightweight aggregate", Construction and Building Materials, v. $\quad 99, \quad$ pp. $\quad 192-199, \quad 2015$, https://doi.org/10.1016/j.conbuildmat.2015.09.036.

\section{ORCID}

Nathaly Santana Leal de Souza

https://orcid.org/0000-0003-0713-4477

Marcos Alyssandro Soares dos Anjos

https://orcid.org/0000-0001-9563-2534

Maria das Vitórias Vieira Almeida de Sá

https://orcid.org/0000-0002-8324-7599

Evilane Cássia de Farias

https://orcid.org/0000-0001-7446-042X

Larissa Cavalcante de Araújo Mello

https://orcid.org/0000-0003-1927-9761 